\title{
A Simplified Determination Method of Dioxin Toxic Equivalent (TEQ) by Single GC/MS Measurement of Five Indicative Congeners
}

\author{
Kotaro Minomo, ${ }^{* \dagger}$ Nobutoshi Ohtsuka, ${ }^{*}$ Kiyoshi NoJIRI,* Shigeo Hosono, ${ }^{*}$ and \\ Kiyoshi KaWAMURA** \\ *Center for Environmental Science in Saitama, 914 Kamitanadare, Kazo, Saitama 347-0115, Japan \\ **Environmental Science and Infrastructure Engineering Division, Graduate School of Science and Engineering, \\ Saitama University, 255 Shimookubo, Sakura, Saitama 338-8570, Japan
}

\begin{abstract}
Here, we proposed a simplified determination method for dioxin (polychlorinated dibenzo- $p$-dioxins, polychlorinated dibenzofurans, and dioxin-like polychlorinated biphenyls (PCBs)) toxic equivalency (TEQ; based on the World Health Organization-2006 toxicity equivalent factor) in environmental samples collected in Japan. This method has estimated the total TEQ from the concentrations of only five indicative congeners, namely, 2,3,4,7,8-pentachlorodibenzofuran; 1,2,3,4,6,7,8-heptachlorodibenzo-p-dioxin; 1,2,3,7,8-pentachlorodibenzo- $p$-dioxin; and PCBs of IUPAC Nos. \#126 and \#105, which were obtained from a single GC/MS measurement using a combination of columns of 10-meter-long DB-5ms (injector side) and 20-meter-long DB-17ms (detector side). Applying this simplified determination method to various environmental samples (ambient air, river water, river sediment, and soil) showed that the estimated TEQ was in good agreement with TEQ obtained by the corresponding official methods. Moreover, this method could estimate the TEQ contributions of the four major dioxin sources in Japan: combustion by-products, pentachlorophenol formulations, chlornitrofen formulations and PCB products.
\end{abstract}

(Received October 20, 2010; Accepted January 28, 2011; Published April 10, 2011)

\section{Introduction}

Polychlorinated dibenzo-p-dioxins (PCDDs), polychlorinated dibenzofurans (PCDFs), and dioxin-like polychlorinated biphenyls (DL-PCBs), hereafter referred to as dioxins, are widespread environmental pollutants. The toxicity of each dioxin congener depends on the number and position of chlorines. For this reason, 2,3,7,8-tetrachlorodibenzo- $p$-dioxin toxic equivalency (TEQ) is generally used for assessment of pollution level. The toxicity equivalent factor (TEF) values are given for 29 dioxin congeners (seventeen 2,3,7,8-chlorinesubstituted PCDDs/PCDFs and twelve DL-PCBs) in the World Health Organization (WHO) TEF systems, ${ }^{1,2}$ and TEQ is evaluated by the sum of the products of each concentration of the 29 TEF congeners and their corresponding TEF values. In order to obtain TEQ, the concentrations of the 29 TEF congeners in total are needed to determine by a gas chromatography/mass spectrometry (GC/MS). However, a capillary column, which is used to separate the 29 TEF congeners from the other congeners, has not yet been reported. Consequently, the official methods for dioxin analysis ${ }^{3-6}$ require three or more-times GC/MS measurements with several types of capillary columns, and take a long measurement time. For example, the measurement conditions described in the JIS K $0312^{4}$ require three or four-times GC/MS measurements with three different capillary

† To whom correspondence should be addressed. E-mail: minomo.kotaro@pref.saitama.lg.jp columns (total measurement time of $113-182 \mathrm{~min}$ ); the condition proposed by Matsumura et al. ${ }^{7}$ needs three-times GC/MS measurements with two different capillary columns (total measurement time, $144 \mathrm{~min}$ ). Quantifying as many as 29 congeners also requires time and efforts. If the number of target congeners can be reduced, it will save a lot of time and efforts for measurement and quantification.

In order to overcome these difficult backgrounds, several methods of simplified determination for dioxins have been investigated. One of them is TEQ estimation using indicative congener(s), whose concentration has a high correlation with TEQ. Fiedler et al. ${ }^{8}$ reported an intriguing observation that the concentration of 2,3,4,7,8-pentachlorodibenzofuran (PeCDF) was proportional to the TEQ, based on the international TEF, ${ }^{9}$ of PCDDs/PCDFs in stack emission gas samples, and proposed a conversion factor from the concentration of 2,3,4,7,8-PeCDF to the TEQ. There were some parallel studies for combustion by-products. It was found that the concentration of 2,3,4,7,8-PeCDF was also proportional to the WHO-1998 TEQ $^{1}$ of PCDDs/PCDFs/DL-PCBs in stack emission gas ${ }^{10,11}$ and ash ${ }^{11}$ samples. Regarding environmental media, to the best of our knowledge, only Shibayama et al. ${ }^{11}$ studied this matter in Japan, and showed that $2,3,4,7,8-\mathrm{PeCDF}$ is suitable as an indicative congener for the determination of the WHO-1998 TEQ of ambient air and soil samples, but another congener in addition to $2,3,4,7,8-\mathrm{PeCDF}$ was needed for water and sediment samples. By using their method, the TEQ of environmental samples may be obtained only from the concentration(s) of indicative congener(s), thus reducing the time and efforts for measurement 
and quantification. However, they also suggested ${ }^{11}$ that estimated TEQ was in disagreement with TEQ obtained by the official method for soil, sediment and water samples in some cases. This may be attributed to the fact that dioxins in the environment in Japan have been brought by multiple sources, as described below. On the basis of previous studies, it has been found that the main sources of dioxin pollution in the environment of $\operatorname{Japan}^{12-25}$ are combustion by-products, pentachlorophenol (PCP) formulations, chlornitrofen (CNP, 4-nitrophenyl 2,4,6-trichlorophenyl ether) formulations, and commercial PCB products. It is well known that dioxins are unintentionally formed during combustion, and are detected in fly ash, bottom ash and flue gas. ${ }^{26-28}$ PCP and CNP formulations, which had been widely used as herbicides in paddy fields in Japan, contain dioxins as impurities. ${ }^{29,30}$ Commercial PCB products have previously been used as heat carriers, dielectric oils, plasticizers and so on, and they also contain dioxins..$^{31,32}$

In our previous study, indicative congeners for the above-mentioned four major dioxin sources were identified and an estimation method of the WHO-1998 TEQs originated from each source was proposed by using only the concentrations of four indicative congeners. ${ }^{33}$ The sum of the TEQ derived from each source estimated by applying the estimation method to various environmental samples in Japan was in good agreement with the actual TEQ; moreover, the method was proved to satisfactorily estimate the TEQ contributions of the four sources. ${ }^{33}$ In our current proposed estimation method, ${ }^{34}$ a fifth indicative congener has been included to the original four congeners so as to make it to be applicable for WHO-2006 TEF system. ${ }^{2}$ This modified method is referred to as the indicative-congener method (ICM) in our further discussions. It is assumed that the ICM could be applied to simplified TEQ determinations, which measure only five indicative congeners. In this case, it would be possible to detect the concentrations of the five indicative congeners by a single GC/MS measurement. Moreover, its application is expected to be useful not only for TEQ determination, but also for source tracing of dioxins because of the ICM's ability of the source apportionment.

In this study, the development of a simplified TEQ determination method based on the ICM was performed, which estimated TEQ from the concentrations of five indicative congeners obtained by a single GC/MS measurement. Firstly, the effectiveness of the ICM was evaluated by applying to environmental samples collected from all over Japan. Secondly, a suitable combination of two GC capillary columns that separated the indicative congeners from the other congeners by single GC/MS measurement was searched.

\section{Materials and Methods}

\section{Indicative congener method}

The indicative congener method (ICM) ${ }^{34}$ was applied to develop a simplified TEQ determination method. The indicative congeners are the following five: $2,3,4,7,8-\mathrm{PeCDF}$ for combustion by-products, 1,2,3,4,6,7,8-heptachlorodibenzo- $p$-dioxin (HpCDD) for PCP formulations, 1,2,3,7,8-pentachlorodibenzo- $p$-dioxin (PeCDD) for CNP formulations, and IUPAC Nos. \#126 and \#105-pentachlorobiphenyls (PeCBs) for PCB products.

The calculation procedure for estimating of TEQ was performed according to the following two steps, as described in a previous paper. $^{34}$ All of the indicative congeners do not originate only from the corresponding source, but also from three other sources. So in the first step, the concentrations of the five indicative congeners originated from the corresponding sources were estimated from their measured concentrations using Eq. (1). In this equation, $C$ denotes the congener concentration, and the subscript and the superscript indicate the congener and the pollution source, respectively. $C$ without any superscript represents the measured congener concentration. If $C_{\mathrm{i}}^{\mathrm{S}}$ (estimated concentration of congener $i$ originated from a pollution source $S$ ) $\leq 0, C_{\mathrm{i}}^{\mathrm{S}}=0$, and if $C_{\mathrm{i}} \mathrm{s} \geq C_{\mathrm{i}}$ (measured concentration of congener $i$ in an environmental sample), $C_{\mathrm{i}}^{\mathrm{S}}=C_{\mathrm{i}}$.

\begin{tabular}{|c|c|c|c|c|c|c|}
\hline 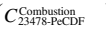 & 1.03 & -0.000641 & -0.0679 & -0.00471 & -0.00000216 & $\left(C_{23478-\mathrm{PeCDF}}\right.$ \\
\hline$C_{1234678-\mathrm{HpCDD}}^{\mathrm{PCP}}$ & -3.62 & 1.00 & 0.239 & 0.0166 & 0.00000760 & $C_{1234678-\mathrm{HpCDD}}$ \\
\hline$C_{12378-\mathrm{PeCDD}}^{\mathrm{CNP}}$ & -0.330 & -0.00151 & 1.02 & 0.00151 & 0.000000693 & $C_{12378-\mathrm{PeCDD}}$ \\
\hline$C_{\# 126-\mathrm{PeCB}}^{\mathrm{PCB}}$ & -0.825 & 0.000514 & 0.0545 & 1.00 & 0.00000173 & $C_{\# 126-\mathrm{PeCB}}$ \\
\hline$C_{\# 115 \mathrm{PC} \cdot \mathrm{PCCB}}^{\mathrm{PCC}}$ & -0.639 & 0.000398 & 0.0422 & 0.00292 & 1.00 & $C_{\# 105 . \mathrm{PeCC}}$ \\
\hline
\end{tabular}

In the second step, the TEQs originated from the four sources are obtained from the five estimated congener concentrations using Eq. (2). The pollution source of the TEQ is indicated in brackets. The estimated total TEQ (TEQ[Total]) is given by Eq. (3):

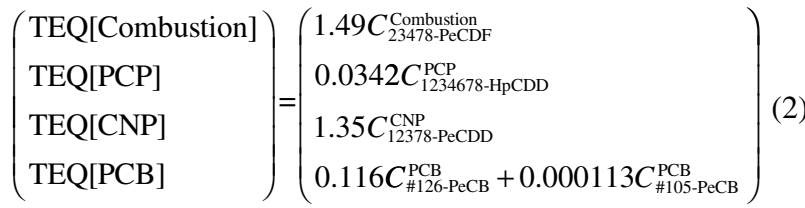

$$
\begin{array}{r}
\mathrm{TEQ}[\text { Total }]=\mathrm{TEQ}[\text { Combustion }]+\mathrm{TEQ}[\mathrm{PCP}]+ \\
\text { TEQ }[\mathrm{CNP}]+\mathrm{TEQ}[\mathrm{PCB}]
\end{array}
$$

\section{Dioxin data of geographic information system (GIS)}

In order to evaluate the applicability of the ICM as a simplified determination method, it was applied to geographic information system (GIS) data for an environmental survey of dioxins in Japan, published on the website of National Institute for Environmental Studies (NIES). ${ }^{35}$ Samples whose concentrations of all 29 congeners with their TEF values exceeding their detection limits were selected from those collected in fiscal 2007 (from April, 2007 to March, 2008). The number of selected samples was 354 for ambient air, 96 for water (river, lake, marine and ground water), 361 for sediment (river, lake and marine sediment), and 354 for soil. The total TEQ for the selected samples was calculated from the 29 congener concentrations based on the WHO-2006 TEF; its range was $0.16-17 \mathrm{pg}-\mathrm{TEQ} / \mathrm{m}^{3}$ for ambient air, $0.23-4.7 \mathrm{pg}-\mathrm{TEQ} / \mathrm{L}$ for water, $0.84-240 \mathrm{pg}-\mathrm{TEQ} / \mathrm{g}$ for sediment, and $0.52-2600$ $\mathrm{pg}-\mathrm{TEQ} / \mathrm{g}$ for soil.

\section{GC/MS measurement}

A high-resolution GC/MS (HP-6890 (Agilent Technologies, Wilmington, DE) + JMS-700 (JEOL, Tokyo, Japan)) was used to detect dioxins. The injector temperature and GC/MS interface temperature were set at 290 and $280^{\circ} \mathrm{C}$, respectively, and helium was used as a carrier gas $(1 \mathrm{~mL} / \mathrm{min})$. The target congeners were separated by using the combination of GC capillary columns, a 10-meter-long DB-5ms $(0.25 \mathrm{~mm}$ i.d., $0.25 \mu \mathrm{m}$ film thickness; Agilent Technologies) and a 20 -meter-long DB-17ms (0.25 mm i.d., $0.25 \mu \mathrm{m}$ film thickness; Agilent Technologies). The GC program was carried out as follows: $130^{\circ} \mathrm{C}(2 \mathrm{~min})$ to $210^{\circ} \mathrm{C}(0 \mathrm{~min})$ at $20^{\circ} \mathrm{C} / \mathrm{min}$ and subsequently to $300^{\circ} \mathrm{C}$ at $3^{\circ} \mathrm{C} / \mathrm{min}$, then maintained at $300^{\circ} \mathrm{C}$ for $4 \mathrm{~min}$ (total: $40 \mathrm{~min}$ ). The MS was operated in the selected ion-monitoring (SIM) mode with a mass resolution of $>10000$ (Lock mass, PFK), 


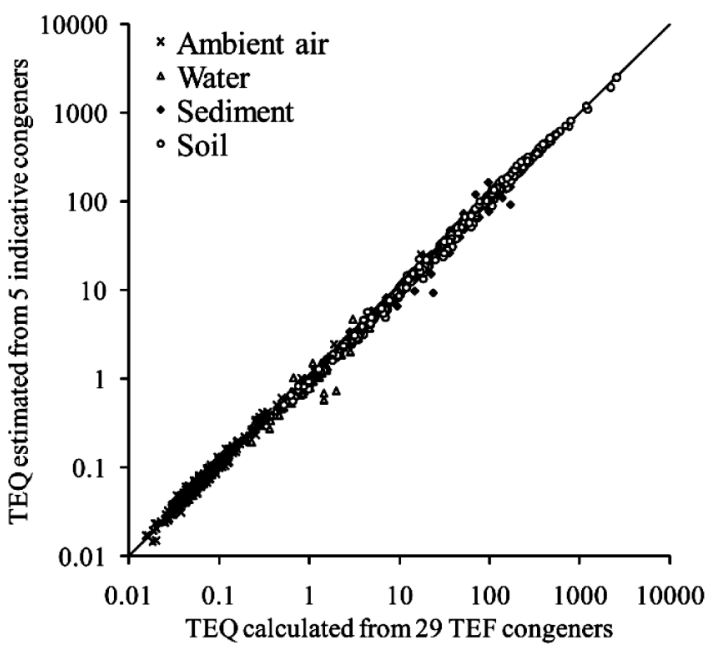

Fig. 1 Relationship between the ICM TEQ and the official-method TEQ for environmental GIS data (354 samples for ambient air, 96 for water, 361 for sediment, and 354 for soil). Unit: $\mathrm{pg}-\mathrm{TEQ} / \mathrm{m}^{3}$ for ambient air, pg-TEQ/L for water, and pg-TEQ/g for sediment and soil.
Table 1 Surveyed results in specific separation of 2,3,4,7,8PeCDF and 1,2,3,7,8-PeCDD on various capillary columns

\begin{tabular}{llccc}
\hline $\begin{array}{c}\text { Capillary } \\
\text { column }\end{array}$ & Polarity & $\begin{array}{c}2,3,4,7,8- \\
\text { PeCDF }\end{array}$ & $\begin{array}{c}1,2,3,7,8- \\
\text { PeCDD }\end{array}$ & Ref. \\
\hline SP-2331 & High & $+^{\mathrm{a}}$ & ++ & 37 \\
CP-Sil88 & High & ++ & ++ & 37 \\
CPS-1 & High & $+^{\mathrm{b}}$ & ++ & 37 \\
DB-225 & Middle & ++ & - $^{\mathrm{d}}$ & 37 \\
DB-210 & Middle & ++ & - & 37 \\
DB-17 & Middle & ++ & + & 37 \\
DB-17ms & Middle & $(++)^{\mathrm{c}}$ & $(-)$ & Current study \\
RH-12ms & (Middle) & ++ & + & 7 \\
DB-5 & Low & - & ++ & 37 \\
DB-5ms & Low & - & ++ & 38 \\
BPX-DXN & (Low) & - & ++ & 7 \\
DB-1 & None & - & + & 37 \\
\hline
\end{tabular}

a. ++ : Baseline separated.

b. +: Partially separated. Distinguishable from neighboring peaks with valley but unsuitable for precise quantification.

c. ( ): Classification by the authors.

d. -: Co-eluted with other congeners. and the electron impact ionization energy was $38 \mathrm{eV}$ with an ion-source temperature of $280^{\circ} \mathrm{C}$. The monitored ions of the target dioxin congener and corresponding isotope-labeled surrogates were as follows: $339.8597 *$ ( $*$ : used for quantification) and 341.8568 for 2,3,4,7,8-PeCDF, 351.9000* and 353.8970 for ${ }^{13} \mathrm{C}_{12}-2,3,4,7,8-\mathrm{PeCDF}, \quad 423.7767^{*}$ and 425.7737 for $1,2,3,4,6,7,8-\mathrm{HpCDD}, \quad 435.8169^{*}$ and 437.8140 for ${ }^{13} \mathrm{C}_{12}-1,2,3,4,6,7,8-\mathrm{HpCDD}, \quad 355.8546 *$ and 353.8576 for 1,2,3,7,8-PeCDD, 367.8949* and 365.8978 for ${ }^{13} \mathrm{C}_{12}-1,2,3,7,8-\mathrm{PeCDD}, 325.8804^{*}$ and 327.8775 for $\# 126 / \# 105-\mathrm{PeCBs}$, and 337.9207* and 339.9178 for ${ }^{13} \mathrm{C}_{12}$-\#126/\#105-PeCBs.

Environmental samples for evaluating the simplified determination method

Various environmental samples, ambient air (Number of samples, $N=26)$, river water $(N=15)$, river sediment $(N=38)$ and soil $(N=29)$, collected in Saitama prefecture from 2004 to 2008 were used to validate the objective simplified method. These samples were pretreated according to the corresponding official methods for dioxin analysis, ${ }^{3-6}$ in which the isotope dilution method by using ${ }^{13} \mathrm{C}$-labeled dioxin surrogates was performed. The dioxin TEQs (based on the WHO-2006 TEF) obtained by the corresponding official methods ranged from 0.038 to $0.51 \mathrm{pg}-\mathrm{TEQ} / \mathrm{m}^{3}$ for ambient air samples, 0.34 to $8.6 \mathrm{pg}-\mathrm{TEQ} / \mathrm{L}$ for river water samples, 3.0 to $78 \mathrm{pg}-\mathrm{TEQ} / \mathrm{g}$ for river sediment samples, and 2.9 to $1500 \mathrm{pg}-\mathrm{TEQ} / \mathrm{g}$ for soil samples.

\section{Results and Discussion}

\section{Validation of the ICM by GIS data}

In our previous study, ${ }^{34}$ the effectiveness of the ICM was evaluated by applying environmental samples collected only from Saitama prefecture. In order to enhance the applicability of the ICM to the objective simplified measurement, Eqs. (1) - (3) were applied to GIS data containing analytical results from all over Japan. The estimated results were compared with the results obtained by the official method, as shown in Fig. 1. The average in the ratio of the ICM TEQ to the official-method TEQ was 1.11 (standard deviation, SD: 0.11) for ambient air, 1.00 (SD: 0.11) for sediment, 1.04 (SD: 0.11) for soil, and 0.98 (SD: 0.17 ) for water. As for water, the value was 0.99 (SD: 0.14), excluding three peculiar samples collected from Mawatashi River in Fukui prefecture, where the water was significantly polluted by dioxins originating from a dye. ${ }^{36}$ Thus, we could prove that ICM is efficient for estimating the TEQ of various environmental samples with a high accuracy for a wide range of TEQ values. This result indicates that the major dioxin sources in the environment in Japan are the above-mentioned four sources (combustion by-products, PCP formulations, CNP formulations and PCB products), and that ICM is applicable to environmental samples collected from any parts of Japan.

\section{Selection of GC column combination}

A GC capillary column combination, which effectively separates the five indicative congeners from the other congeners, was searched from commercially available columns. Among the five indicative congeners, the chromatographic isolation of $2,3,4,7,8-\mathrm{PeCDF}$ and $1,2,3,7,8-\mathrm{PeCDD}$ by a same column was of interest in the present study. Table 1 gives the separation capacity of various capillary columns for the two congeners. Only these columns with a stationary phase of high polarity, such as SP-2331 and CP-Sil88, can isolate the two congeners from the other congeners. Therefore, it may be possible to separate the indicative congeners from the other congeners by a single GC/MS measurement with these high-polarity columns. However, when a simplified determination method is applied for a screening survey that deals with a large number of samples, a column having a stable stationary phase of lower polarity is more manageable than a sensitive one with a high-polar stationary phase. Thus, a low-polarity column, DB-5ms (0.25 mm i.d., $0.25 \mu \mathrm{m}$ film thickness), which separates $1,2,3,7,8$-PeCDD from the other congeners, a middle polarity column, DB-17ms (0.25 mm i.d., $0.25 \mu \mathrm{m}$ film thickness), which separates $2,3,4,7,8$-PeCDF from the other congeners, and their combinations were examined. The column combinations examined were as follows: (i) 30-meter-long DB-5ms, (ii) 20-meter-long DB-5ms +10 -meter-long DB- $17 \mathrm{~ms}$, (iii) 10 -meter-long DB-5ms + 20-meter-long DB-17ms, and (iv) 
30-meter-long DB-17ms. The DB-5ms column was set at the injector side because the column bleed from the low-polarity stationary phase of DB-5ms is expected to be smaller than that from the higher polarity one of DB- $17 \mathrm{~ms}$. Another reason for the order of the columns is that all seventeen 2,3,7,8-chlorinesubstituted PCDDs/PCDFs were successfully isolated by only one injection with $\mathrm{GC} \times \mathrm{GC}$, in which the 5-like GC column (InterCap 5MS/Sil; GL Science, Tokyo, Japan) as the first column and 17-like GC column (InterCap 17MS/Sil; GL Science) as the second column were installed..$^{39}$ Conditioning of the columns was carried out separately before connection. Non-polar fused-silica tubes (Supelco, Bellefonte, PA) were set at the both ends of the columns; $2 \mathrm{~m} \times 0.32 \mathrm{~mm}$ i.d. for injector side, and $2 \mathrm{~m} \times 0.25 \mathrm{~mm}$ i.d. for detector side.

Among the various environmental media, sediment is thought to be one of the meaningful sinks of dioxins, because dioxins are transported to sediment through air deposition, ${ }^{15}$ rainfall, ${ }^{40}$ water inflow ${ }^{24}$ etc. In fact, the dioxins in the sediment samples in Japan are considered to be attributed to various sources, PCP and CNP formulations, ${ }^{12-14,17-19,21,23}$ combustion by-products, ${ }^{14,17-19,22,25}$ and commercial PCB products. ${ }^{16,17,22,25}$ For this reason, sediment samples were applied to the four column combinations to search for a suitable combination for an objective simplified determination method. Table 2 gives the average in the ratio of the indicative congener concentration measured with the tested column combinations to that measured

Table 2 Average in ratio of the indicative congener concentration in sediment samples $(N=38)$ measured with selected column combination to that measured by the official method

\begin{tabular}{|c|c|c|c|c|}
\hline \multirow[b]{2}{*}{ Indicative congener } & \multicolumn{4}{|c|}{ Column combination ${ }^{\mathrm{a}}$} \\
\hline & $\begin{array}{c}\mathrm{i} \\
\text { DB-5ms: } \\
30 \mathrm{~m}\end{array}$ & $\begin{array}{c}\text { ii } \\
\text { DB-5ms: } \\
20 \mathrm{~m}+ \\
\text { DB-17ms: } \\
10 \mathrm{~m}\end{array}$ & $\begin{array}{c}\text { iii } \\
\text { DB-5ms: } \\
10 \mathrm{~m}+ \\
\text { DB-17ms: } \\
20 \mathrm{~m}\end{array}$ & $\begin{array}{l}\text { DB-17ms: } \\
30 \mathrm{~m}\end{array}$ \\
\hline 2,3,4,7,8-PeCDF & $1.28(0.20)^{t}$ & b $3.26(0.56)$ & $1.02(0.13)$ & $1.03(0.15)$ \\
\hline 1,2,3,7,8-PeCDD & $1.13(0.16)$ & $1.00(0.12)$ & $1.07(0.15)$ & $1.33(0.18)$ \\
\hline $1,2,3,4,6,7,8-\mathrm{HpCDD}$ & $1.06(0.08)$ & $1.10(0.08)$ & 1.03 & $1.11(0.10)$ \\
\hline \#126-РeCВ & $0.93(0.08)$ & $0.99(0.09)$ & $1.03(0.10)$ & $0.94(0.08)$ \\
\hline \#105-PeCB & $0.95(0.06)$ & $0.99(0.06)$ & $1.01(0.07)($ & $0.96(0.06)$ \\
\hline
\end{tabular}

a. DB-5ms, injector side; DB- $17 \mathrm{~ms}$, detector side.

b. Standard deviation values are given in parentheses. by the official method. ${ }^{5}$ The value for $2,3,4,7,8-\mathrm{PeCDF}$ was almost 1 (range: $1.02-1.03$ ) with the column combinations iii and iv, while it was larger with the column combinations $i$ and ii. On the other hand, the value for 1,2,3,7,8-PeCDD was almost 1 (range: $1.00-1.13$ ) with the column combinations i, ii and iii, while it was larger with the column combination iv. As for the other three indicative congeners $(1,2,3,4,6,7,8-\mathrm{HpCDD}$, $\# 126-\mathrm{PeCB}$ and \#105-PeCB), the value was almost 1 (range: $0.93-1.03$ ) with all the column combinations. Figure 2 illustrates an example of GC/MS chromatograms of the five indicative congeners in a tested sediment sample measured with the column combination iii. The peaks of \#105-/\#126-PeCBs and $1,2,3,4,6,7,8-\mathrm{HpCDD}$ were perfectly isolated. Though the peaks of 2,3,4,7,8-PeCDF and 1,2,3,7,8-PeCDD were observed
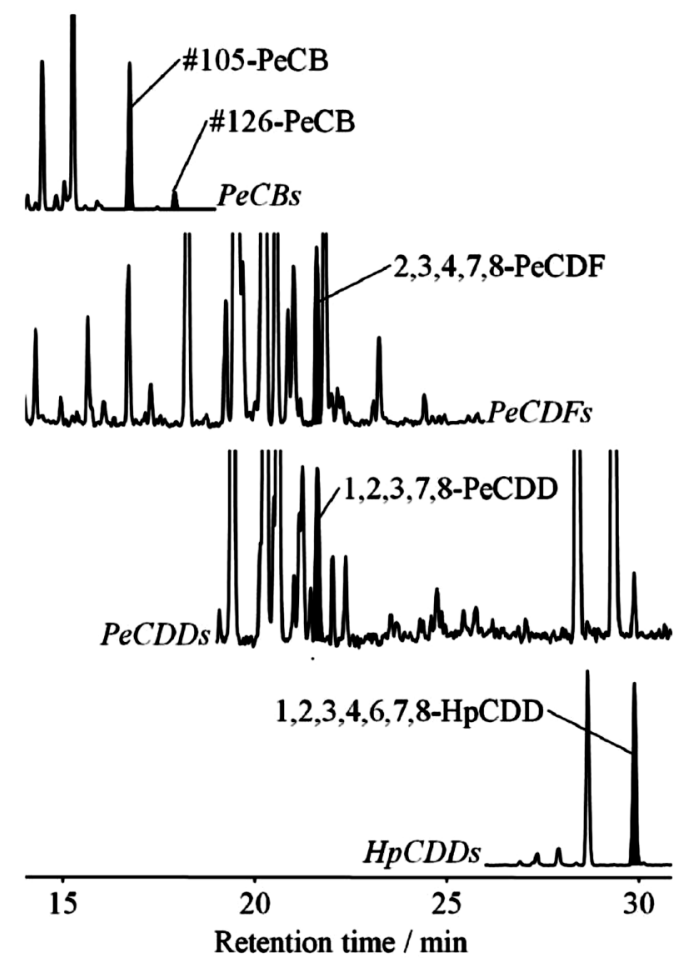

Fig. 2 Example of GC/MS chromatograms of the five indicative congeners in a sediment sample measured with the column combination iii (10-meter-long DB-5ms + 20-meter-long DB-17ms).

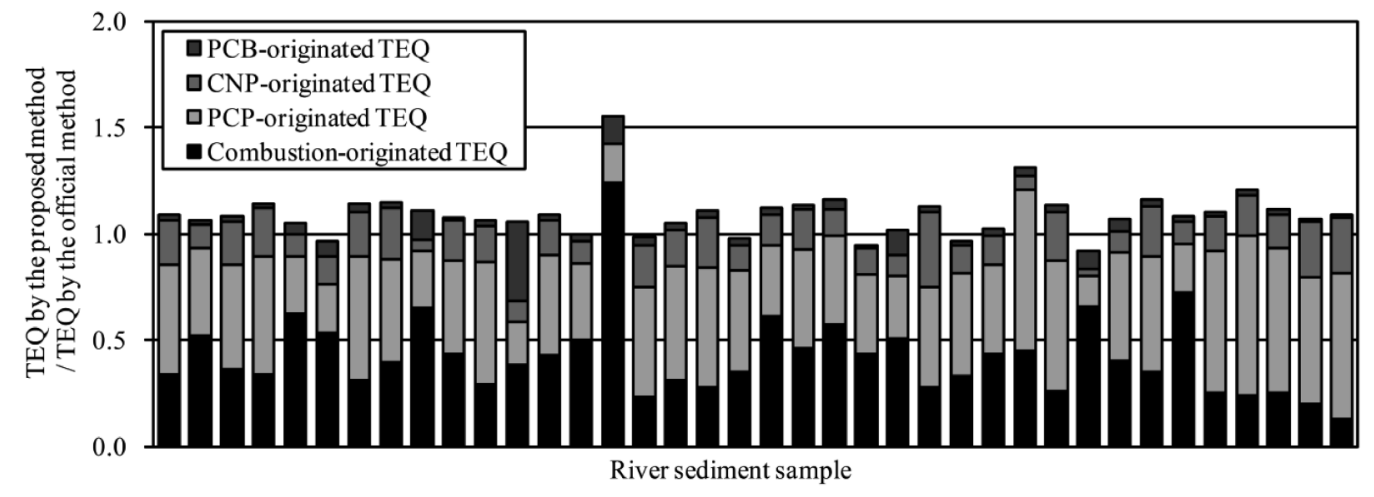

Fig. 3 Summarized results in the ratio of TEQ by the proposed method to TEQ by the official method for river sediment samples. 
very closely to each neighboring peak, they were separated enough for precise quantification; the degree of separation between the 2,3,4,7,8-PeCDF peak and its nearest one, and that between 1,2,3,7,8-PeCDD and its nearest one were 1.21 (range: $1.15-1.34$ ) and 1.27 (range: $1.09-1.50$ ), respectively. As results, the column combination iii showed a good separation capacity of the five indicative congeners from the other congeners.

Figure 3 shows the result of TEQ for the all of sediment samples, measured using the proposed method with the column combination iii. The TEQ obtained with the proposed method was in good agreement with the official-method TEQ, showing that the average in the ratio of the former to the latter was 1.09 and the SD of the ratio was 0.11. It was shown that the column combination iii was suitable for the objective measuring method.

Application to samples obtained from various environmental media

The five indicative congeners in the ambient air, river water and soil samples were also measured with the column combination iii. As shown in Table 3, the average in the ratio of the indicative congener concentration in various environmental media measured with the column combination iii to that measured by the corresponding official methods ${ }^{3,4,6}$ was almost 1 for all congeners. The results of TEQ are shown in Fig. 4. The estimated TEQ was in good agreement with the official-method TEQ for samples collected from all environmental media, and the average in the ratio of the former to the latter was 1.08 (SD: 0.08) for ambient air samples, 1.14 (SD: 0.12) for river water samples and 1.00 (SD: 0.08) for soil samples. Therefore, the proposed simplified TEQ determination

Table 3 Average in the ratio of the indicative congener concentration in various environmental media measured with column combination iii to that measured by the corresponding official methods

\begin{tabular}{lccc}
\hline \multicolumn{1}{c}{ Indicative congener } & $\begin{array}{c}\text { Ambient air } \\
N=26\end{array}$ & $\begin{array}{c}\text { River water } \\
N=15\end{array}$ & $\begin{array}{c}\text { Soil } \\
N=29\end{array}$ \\
\hline $2,3,4,7,8-\mathrm{PeCDF}$ & $0.99(0.12)^{\mathrm{a}}$ & $1.01(0.18)$ & $0.95(0.07)$ \\
$1,2,3,7,8-\mathrm{PeCDD}$ & $0.95(0.14)$ & $0.97(0.17)$ & $1.03(0.10)$ \\
$1,2,3,4,6,7,8-\mathrm{HpCDD}$ & $1.06(0.05)$ & $1.14(0.09)$ & $0.99(0.07)$ \\
$\# 126-\mathrm{PeCB}$ & $1.04(0.07)$ & $0.99(0.07)$ & $1.03(0.07)$ \\
$\# 105-\mathrm{PeCB}$ & $1.04(0.04)$ & $1.04(0.04)$ & $1.01(0.06)$ \\
\hline
\end{tabular}

a. Standard deviation values are given in parentheses. method was proved to be adoptable for various environmental media in Japan. Compared with the JIS K 0312, this method largely reduced the time to only $22-35 \%$ in the measurement. Considering the column exchange and quantification, the reduction of time and efforts are more significant.

In addition to total TEQ, the proposed method can estimate the TEQ contributions of each source (Figs. 3 and 4). This aspect will be useful for tracing dioxin pollution sources. No such simplified TEQ determination method has yet been reported to the best of our knowledge.

\section{Potential for development of the proposed method}

The time required for the GC/MS measurement applied in this study was approximately $40 \mathrm{~min}$. The measurement time will be shortened with the development of a column dimension, GC temperature program and so on. In this method, only five congeners are required to be monitored and, therefore, the sensitivity of the detector may be improved. Thus, the sample size is expected to be reduced. Moreover, a general-purpose detector, such as a lower resolution MS, may be adoptable instead of a high-resolution one. However, as shown in Fig. 3, the retention times of $2,3,4,7,8-\mathrm{PeCDF}$ and $1,2,3,7,8-\mathrm{PeCDD}$ are almost the same; the monitoring ion channel of $1,2,3,7,8$-PeCDD $(\mathrm{m} / \mathrm{z}=355.8546)$ may be interfered by the mass channel of $355.8941\left({ }^{13} \mathrm{C}-2,3,4,7,8\right.$-PeCDF $)$ at a lower mass resolution. A lower resolution MS detector may require careful use.

The application of the proposed method is limited for environmental samples collected in Japan, because the proposed method is designed with focus on the major pollution sources in Japan. However, the underlying concept of the method will be applicable to any other geographic regions by modifying the equations for the TEQ calculation and selecting proper GC columns.

\section{Conclusions}

A simplified determination method of dioxin TEQ was established based on the concentrations of only five indicative congeners $(2,3,4,7,8$-PeCDF, $1,2,3,4,6,7,8-\mathrm{HpCDD}, 1,2,3,7,8$ PeCDD, and PCBs of IUPAC Nos. \#126 and \#105) obtained by single GC/MS measurement. The five indicative congeners were separated from the other congeners with a GC column combination of 10-meter-long DB-5ms (injector side) and 20-meter-long DB-17ms (detector side). Applying the method to various environmental samples collected from ambient air,

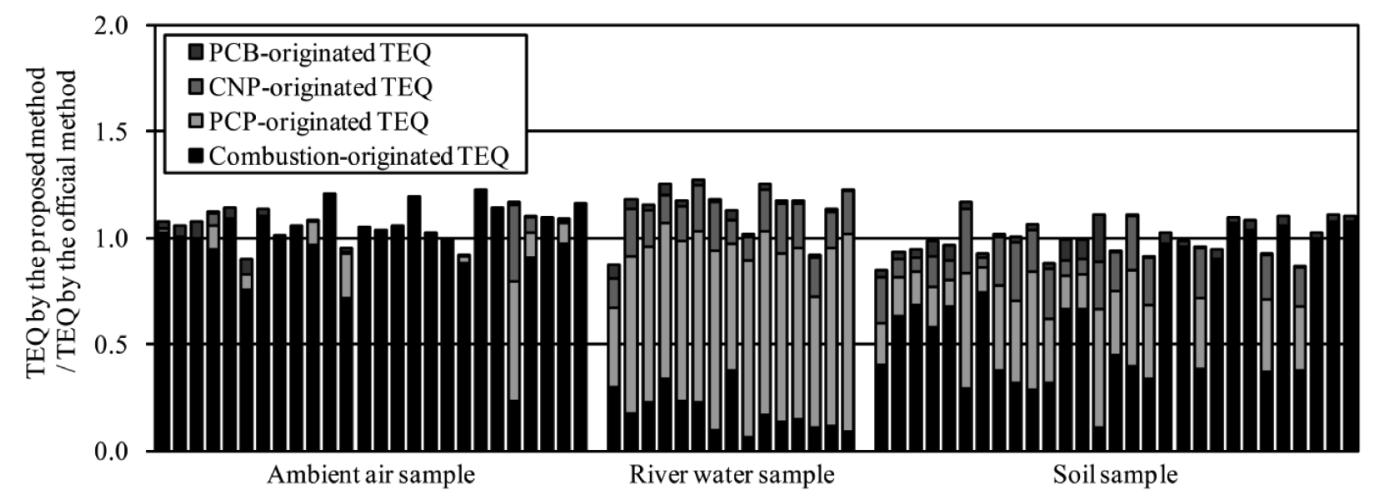

Fig. 4 Summarized results in the ratio of TEQ by the proposed method to TEQ by the official method for ambient air, river water and soil samples. 
river water, river sediment and soil showed that the estimated TEQ was in good agreement with the official-method TEQ.

\section{References}

1. M. van den Berg, L. Birnbaum, A. T. C. Bosveld, B. Brunström, P. Cook, M. Feeley, J. P. Giesy, A. Hanberg, R. Hasegawa, S. W. Kennedy, T. Kubiak, J. C. Larsen, F. X. Rolaf van Leeuwen, A. K. Djien Liem, C. Nolt, R. E. Peterson, L. Poellinger, S. Safe, D. Schrenk, D. Tillitt, M. Tysklind, M. Younes, F. Wærn, and T. Zacharewski, Environ. Health Perspect., 1998, 106, 775.

2. M. van den Berg, L. S. Birnbaum, M. Denison, M. De Vito, W. Farland, M. Feeley, H. Fiedler, H. Hakansson, A. Hanberg, L. Haws, M. Rose, S. Safe, D. Schrenk, C. Tohyama, A. Tritscher, J. Tuomisto, M. Tysklind, N. Walker, and R. E. Peterson, Toxicol. Sci., 2006, 93, 223.

3. "Manual on Determination of Dioxins in Ambient Air (in Japanese)", Office of Dioxin Control \& Air Quality Management Division, Environmental Management Bureau, Ministry of the Environment, 2001, Japan.

4. JIS K 0312, "Method for Determination of tetra- through octa-Chlorodibenzo- $p$-dioxins, tetra- through octaChlorodibenzofurans and Coplanar Polychlorobiphenyls in Industrial Water and Waste Water", 1999, Japanese Standards Association, Tokyo.

5. "Manual on Determination of Dioxins in Sediment (in Japanese)", 2000, Water Quality Management Division, Water Quality Bureau, Environmental Agency, Government of Japan.

6. "Manual on Determination of Dioxins in Soil (in Japanese)", 2000, Soil and Agricultural Chemicals Division, Water Quality Bureau, Environmental Agency, Government of Japan.

7. T. Matsumura, Y. Seki, Y. Masuzaki, M. Morita, and H. Ito, in Programs and Abstracts of the 11th Symposium on Environmental Chemistry (in Japanese), 2002, 152 - 153.

8. H. Fiedler, C. Lau, and G. Eduljee, Waste Manage. Res., 2000, 18, 283.

9. F. W. Kutz, D. G. Barnes, E. W. Bretthauer, D. P. Bottimore, and H. Greim, Toxicol. Environ. Chem., 1990, 26, 99.

10. K. Urano and M. Kato, Organohalogen Compounds, 2001, $54,364$.

11. M. Shibayama, A. Hayashi, T. Inoue, and T. Takasuga, J. Environ. Chem., 2003, 13, 17.

12. T. Sakurai, J.-G. Kim, N. Suzuki, and J. Nakanishi, Chemosphere, 1996, 33, 2007.

13. T. Sakurai, N. Suzuki, S. Masunaga, and J. Nakanishi, Chemosphere, 1998, 37, 2211.

14. S. Masunaga, Y. Yao, I. Ogura, S. Nakai, Y. Kanai, M. Yamamuro, and J. Nakanishi, Environ. Sci. Technol., 2001, 35, 1967.

15. I. Ogura, S. Masunaga, and J. Nakanishi, Chemosphere, 2001, 45, 173.

16. T. Sakurai, N. Suzuki, and M. Morita, Chemosphere, 2002,
46, 1359.

17. Y. Yao, S. Masunaga, H. Takada, and J. Nakanishi, Environ. Toxicol. Chem., 2002, 21, 991.

18. S. Masunaga, Y. Yao, I. Ogura, T. Sakurai, and J. Nakanishi, Chemosphere, 2003, 53, 315.

19. T. Sakurai, Environ. Sci. Technol., 2003, 37, 3133.

20. S. Iwamoto, T. Matsueda, Y. Kurokawa, K. Ohno, K. Tobiishi, and K. Sakuragi, J. Environ. Chem., 2004, 14, 805.

21. J. Kobayashi, H. Kajihara, and Y. Takahashi, J. Environ. Chem., 2004, 14, 109.

22. I. Ogura, M. Gamo, S. Masunaga, and J. Nakanishi, Environ. Toxicol. Chem., 2005, 24, 277.

23. O. Kiguchi, T. Kobayashi, Y. Wada, K. Saitoh, and N. Ogawa, Chemosphere, 2007, 67, 557.

24. N. Seike, N. Kashiwagi, and T. Otani, Environ. Sci. Technol., 2007, 41, 2210.

25. K. Ohba, H. Katsumata, M. Watanabe, N. Suzuki, S. Kaneco, T. Suzuki, and K. Ohta, Bunseki Kagaku, 2009, 58, 81.

26. K. Olie, P. L. Vermeulen, and O. Hutzinger, Chemosphere, 1977, 6, 455.

27. M. Hiraoka, Y. Takizawa, Y. Masuda, R. Takeshita, K. Yagome, M. Tanaka, Y. Watanabe, and K. Morikawa, Chemosphere, 1987, 16, 1901.

28. S. Sakai, M. Hiraoka, N. Takeda, and K. Shiozaki, Chemosphere, 1993, 27, 233.

29. S. Masunaga, T. Takasuga, and J. Nakanishi, Chemosphere, 2001, 44, 873.

30. N. Seike, T. Otani, M. Ueji, T. Takasuga, and N. Tsuzuki, $J$. Environ. Chem., 2003, 13, 117.

31. T. Wakimoto, N. Kannan, M. Ono, R. Tatsukawa, and Y. Masuda, Chemosphere, 1988, 17, 743.

32. Y. Noma, Y. Ishikawa, K. Nose, K. Minetomatsu, H. Takigami, S. Sakai, S. Izumisawa, and Y. Kaburaki, J. Environ. Chem., 2004, 14, 501.

33. N. Ohtsuka, S. Hosono, K. Nojiri, and K. Minomo, J. Environ. Chem., 2007, 17, 377.

34. K. Minomo, N. Ohtsuka, K. Nojiri, S. Hosono, and K. Kawamura, Chemosphere, 2010, 81, 985.

35. GIS Data for Environmental Survey of Dioxins, Compilation prepared by NIES (in Japanese), http://www-gis2.nies.go.jp/ dioxin/.

36. H. Kumagai, Y. Fujii, and T. Kanbe, Annual Report of Fukui Prefectural Institute of Public Health and Environmental Science (in Japanese), 2005, 4, 66.

37. J. J. Ryan, H. B. S. Conacher, L. G. Panopio, B. P.-Y. Lau, J. A. Hardy, and Y. Masuda, J. Chromatogr., 1991, 541, 131 .

38. E. Abad, J. Caixach, and J. Rivera, J. Chromatogr., A, 1997, $786,125$.

39. S. Hashimoto, Y. Takazawa, A. Fushimi, H. Ito, K. Tanabe, Y. Shibata, M. Ubukata, A. Kusai, K. Tanaka, H. Otsuka, and K. Anezaki, J. Chromatogr., A, 2008, 1178, 187.

40. B. D. Eitzer and R. A. Hites, Environ. Sci. Technol., 1989, 23, 1396. 